\title{
DEPRESSÃO INFANTIL: UMA REALIDADE PRESENTE NA ESCOLA
}

CARMO, Alessandra Lopes do ${ }^{1}$ SILVA, Ana Paula Barrozo da ${ }^{1}$ TRONCOSO, Ana Cristina ${ }^{2}$

Recebido em: 2009-07-06

Aprovado em: 2009-09-23

ISSUE DOI: $10.3738 / 1982.2278 .180$

RESUMO: A presente pesquisa teve por objetivo investigar o conhecimento que os professores têm a respeito da depressão infantil, analisar a postura que médicos e psicólogos adotam durante o tratamento da depressão em crianças e levantar dados sobre a incidência da depressão infantil em uma escola pública da cidade de Ituverava. Para isso, realizou-se pesquisa bibliográfica para conhecer a doença, seus sintomas e tratamentos, bem como o papel do professor diante de casos de depressão na sala de aula. Utilizou-se como fonte de levantamento de informações, a aplicação de questionários para os professores profissionais que lidam com crianças depressivas. Também se utilizou o Inventário da Depressão Infantil para identificar alunos com sintomatologia depressiva.

Palavras-chave: Depressão infantil. Transtornos emocionais. Sintomas. Tratamento. Inventário de Depressão infantil. Professor.

SUMMARY: The current resource has the objective to investigate the knowing that teachers have regard children depression, analyses the doctors and psychologists adopt during the depression care in children and quantify data about the incidence of children's depression at a public school in Ituverava City. For this, realized bibliographic resource to meeting the disease, the symptoms and care, as like as the teacher's actuation in front of the depression cases at classes. Used too, like source of information the application of questionnaires to teacher professionals who work with depressive children. The Children Depression Inventory was used too, like identify pupils with depression symptoms.

Keywords: Children Depression. Emotional troubles. Symptoms. Care. Children Depression Inventory (CDI).

\section{INTRODUÇÃO}

Por muito tempo acreditou-se que a depressão em crianças não existia, ou que seria muito rara. Dessa forma o reconhecimento da depressão infantil é bastante recente. Segundo Cruvinel e Boruchovitch (2004), a depressão é considerada um transtorno de humor que, ocorrendo na infância, vem acompanhado de problemas escolares, como

\footnotetext{
${ }^{1}$ Graduadas em Pedagogia. E- mail: aleka.lopes@ @otmail.com

${ }^{2}$ Dra. em Psicologia. Chefe do laboratório De Neurociências e Comportamento - UFF-Universidade Federal Fluminense.
} 
dificuldades de aprendizagem, concentração e problemas de comportamento, como isolamento ou agitação.

Segundo Miller (2003), no início do século XX, Freud não acreditava que as crianças tivessem estruturas psicológicas formadas para vivenciar a depressão e no caso dos adolescentes os sintomas eram taxados como normais e simplesmente fases do seu desenvolvimento.

Na década de 1940, René Spitz e John Bowlby observaram, durante seus estudos sobre o apego, que bebês entre seis meses e três anos de idade, quando separados de suas mães, apresentavam sintomas como expressão triste, incapacidade de interagir, recusa a comer, murmúrios e reclusão. Ficou assim evidente um quadro de sintomas depressivos nesta fase tão precoce da vida, em conseqüência de fatores traumáticos e estressores. Ainda pesquisando sobre o apego, Harlow desenvolveu uma experiência com filhotes de macacos rhesus que comprovou que a necessidade do contato físico do bebê com a mãe é tão importante quanto a alimentação e que se o bebê for privado deste contato poderá futuramente desenvolver conseqüências patológicas, além de perturbações emocionais graves. (CARDOSO, 2001)

Apesar de afetar o comportamento da criança em casa, na escola e nos seus relacionamentos (CRUVINEL; BORUCHOVITCH, 2004), a existência da depressão em crianças só começou a ser aceita na década de 1960. A partir deste reconhecimento houve um grande aumento nas pesquisas e o alerta que a depressão em crianças e adolescentes tem aumentado nas últimas décadas. Para Cruvinel e Boruchovitch (2004), a dificuldade dos pais e educadores em identificar os sintomas da depressão agrava ainda mais a situação, deixando a criança sem receber orientação e tratamento adequados.

\section{O QUE É A DEPRESSÃO}

De acordo com Miller (2003), a depressão é um transtorno de humor, que se manifesta através de um conjunto de sintomas, que alteram o pensamento, comportamento, sentimentos e fisiologia da pessoa deprimida, durante um período significativo de tempo, sendo no mínimo duas semanas.

Segundo as pesquisas relatadas por Bahls (2004), alguns pesquisadores afirmam que a partir dos 6 meses de idade é possível a manifestação de sintomas depressivos, como atraso no desenvolvimento motor, falta de apetite, alterações do sono, choro 
excessivo sem motivo orgânico, desinteresse e poucas respostas aos estímulos do ambiente, irritabilidade e hipoatividade.

A depressão em crianças pré-escolares se manifesta de forma marcante através de ansiedade, fobias, hiperatividade, irritabilidade, alterações no sono e no apetite, dores somáticas e prazer diminuído nas atividades que antes. (BAHLS, 2004)

A depressão em crianças com idade escolar é freqüente e a expressão de humor depressivo manifesta-se através de queixas de tristeza e de tédio. A irritabilidade é ainda mais marcante e acompanhada de choro fácil. O declínio no desempenho escolar representa um dos principais problemas da depressão precoce, e pode auxiliar na identificação do quadro depressivo. É causado pela dificuldade de concentração ou falta de interesse. As fobias, ansiedade de separação e dores somáticas podem levar a recusa $\mathrm{a}$ ir à escola, bem como o isolamento e dificuldade em fazer amigos.

\section{TRATAMENTO}

A criança com depressão necessita de um diagnóstico rápido e, para garantir uma boa recuperação, é indispensável que os pais estejam bem informados sobre o assunto.

Na depressão infantil, as psicoterapias são muito indicadas para tratamento, especialmente nos casos de sintomas mais leves. Busca-se ajudar o paciente e os familiares a criarem habilidades para enfrentar as situações de conflito e lidar com as sequelas psicossociais causadas pela depressão.

Os principais objetivos da psicoterapia, de acordo com Bahls (2004) são: alívio dos sintomas, busca do restabelecimento das funções e habilidades do paciente e, finalmente, prevenção de um novo episódio depressivo.

De acordo com Miller (2003) o medicamento para transtornos de humor na infância deve ser prescrito em última instância, com a indicação de um médico, que poderá ser o próprio pediatra da criança ou um psiquiatra. A decisão de usar medicamentos na depressão infantil baseia-se na gravidade, duração dos sintomas e, quando houver dificuldade de aliviá-los, através de terapias.

\section{A DEPRESSÃO INFANTIL NA ESCOLA}


De acordo com Jean-Jaques Hemery (2008), a família constitui o primeiro meio que a criança tem para se relacionar com o mundo e construir a sua personalidade.

Depois é que a criança passa a se relacionar com outros ambientes, tendo na escola um espaço privilegiado para a participação ativa na vida dessas crianças.

A depressão infantil deixa de ser um problema individual ou familiar, pois a escola tem um papel fundamental na identificação e auxílio para o encaminhamento a profissionais qualificados para o tratamento de seus alunos com sintomas depressivos, sendo de extrema importância que os professores conheçam esse transtorno de humor, que "além de envolver fatores afetivos, apresenta também componentes cognitivos, comportamentais, motivacionais e fisiológicos" (CRUVINEL; BORUCHOVITCH, 2004).

Os professores geralmente são os primeiros a perceberem a depressão infantil, pois ela envolve um conjunto de sintomas, com importantes alterações no comportamento, que se apresenta diversificadamente no âmbito escolar, sendo que um dos primeiros indícios seria a queda no rendimento escolar, pois "o declínio no desempenho pode dever-se à fraca concentração ou à falta de interesse, próprios do quadro depressivo" (BAHLS, 2004).

Um dos aspectos que apontam a importância do papel do docente para o diagnóstico de algum transtorno de humor nas crianças é o fato de, ao contrário dos pais, o professor ter um conhecimento maior sobre o desenvolvimento infantil.

O educador não é responsável pelo diagnóstico, por não ter qualificação profissional para isso e por ser uma tarefa bastante delicada, mas pode contribuir - e muito - na identificação dos sintomas e na indicação para avaliação clínica. É necessário ao educador o conhecimento sobre esta doença que é cada vez mais comum nas crianças. Quando for observada alguma manifestação de sintomas depressivos, a primeira atitude do professor deve ser conversar com os pais para entender melhor o que se passa na vida do aluno e sugerir que o levem para uma avaliação clínica, com psicólogo, pediatra ou psiquiatra. (HEMERY, 2008)

Quando a depressão infantil for diagnosticada por profissionais especializados, passa a ser fundamental a integração entre todos os envolvidos com a criança, com o objetivo de tornar mais eficaz o tratamento e a recuperação.

\section{UNIVERSO DA PESQUISA}

Nucleus, v.6, n.2, out. 2009 
Participaram da pesquisa crianças de terceira e quarta série para estudo da manifestação da depressão. Também participaram oito professoras da rede pública de

ensino fundamental, uma psicóloga judiciária, um psiquiatra, três psicólogas, sendo duas do Departamento de Saúde Mental do Município e uma atua em consultório particular.

\section{- AS CRIANÇAS}

Foram selecionadas três turmas de alunos para a participação da pesquisa, sendo duas turmas de terceira série e uma de quarta série, totalizando 73 alunos com idade de 9 a 12 anos.

Foi enviado aos pais, por intermédio dos alunos, um termo de autorização para participação da pesquisa, esclarecendo o propósito da mesma. Sendo assim, os alunos que não tiveram consentimento de seus pais ou não estavam presentes não responderam a pesquisa, participando então 42 alunos, o que representa 58\% do total da amostra, composta por alunos de ambos os sexos, em que vinte e dois alunos eram do sexo feminino e vinte alunos do sexo masculino.

\section{- OS PROFISSIONAIS}

Responderam ao formulário cinco professoras que lecionam na rede pública de ensino de primeira a quarta série do Ensino Fundamental, sendo que a experiência profissional varia de um (01) a trinta e cinco (35) anos de trabalho docente.

Participou da pesquisa uma psicóloga que atua há 17 anos com crianças nas Varas da Infância, Juventude, Família e Sucessões. Também foram convidadas três psicólogas que trabalham com psicoterapia, porém duas dessas psicólogas, que atuam no Departamento de Saúde Mental do município, não responderam o questionário, alegando que as questões eram difíceis e necessitavam pesquisar sobre o assunto para poderem responder.

Respondeu o questionário, um médico psiquiatra do Departamento de Saúde Mental do município, com nove anos de experiência na área da psiquiatria e há cinco anos trabalhando com crianças.

\section{PROCEDIMENTOS}


Para o estudo da incidência da depressão, foi utilizado o $\mathrm{CDI}^{3}$ - Inventário da Depressão Infantil. Foi esclarecido aos alunos o caráter confidencial do estudo e que

suas respostas não iriam interferir no seu desempenho escolar. A aplicação do CDI foi feita pelas próprias pesquisadoras, que deram todas as instruções sobre as questões, bem como a leitura das mesmas, mediante as possíveis dificuldades de leitura e interpretação dos alunos. A duração do teste variou entre 30 e 50 minutos.

Foi escolhido para desenvolvimento da pesquisa o CDI pela sua facilidade de aplicação e coleta de dados, e pela visão geral que ele oferece sobre os sintomas depressivos que a criança pode apresentar.

Consiste em identificar sintomas da depressão infantil em pessoas de sete (07) a dezessete (17) anos de idade, através de auto-avaliação ou por resposta de informantes, como por exemplo, pais e professores, tendo como referência para a resposta pelo menos as últimas duas semanas. O CDI contém ao todo 27 questões, com itens distribuídos entre sintomas afetivos, cognitivos e comportamentais.

Para os profissionais foi elaborado um questionário com perguntas específicas para a área de atuação de cada um.

\section{RESULTADOS}

\section{- A INCIDÊNCIA DA DEPRESSÃO INFANTIL}

Vinte dos quarenta e dois alunos, ou seja, 48\% da amostra demonstraram sintomatologia depressiva considerável. Não houve manifestação significativa de acordo com o sexo da criança. Isso pode ocorrer devido à faixa etária pesquisada, pois segundo alguns autores é a partir da puberdade que a depressão prevalece no sexo feminino. Nesse estudo, doze dos alunos com sintomas depressivos eram do sexo masculino, enquanto oito eram do sexo feminino.

Das 27 questões que formam o CDI, a que mais chama atenção é a questão de número nove, que se refere ao pensamento suicida. Após a aplicação do CDI, a análise dos dados evidenciou que houve nesta amostra o pensamento suicida, pois vinte e uma crianças responderam que pensam em se matar, mas que não fariam isso, e ainda duas crianças afirmam que querem se matar.

${ }^{3}$ Children Depression Inventary (do inglês)

Nucleus, v.6, n.2, out. 2009 
É importante lembrar que a intenção suicida é apenas um dos sintomas presentes na depressão, sendo necessário avaliar o conjunto de sintomas que a pessoa apresenta e sua persistência para que esta seja considerada como depressiva. Isto se reflete também

no presente estudo, já que seis (06) dos vinte e um (21) alunos que pensam em se matar, mas que não fariam isso, não alcançaram escore significativo para que a incidência da depressão seja confirmada, enquanto as duas crianças que responderam que querem se matar obtiveram pontuações altas, sendo uma com 25 pontos e outra com 34 pontos, sendo identificado estado depressivo.

\section{- PROFESSORAS}

Foi unânime entre as docentes a observação de problemas emocionais em seus alunos, sendo comuns problemas como hiperatividade, agressividade, carência afetiva, apatia, desinteresse e dificuldade de atenção e de concentração.

As professoras afirmam conhecer a depressão infantil, por meio de palestras, psicólogos, pesquisa e durante o curso superior. Elas relatam alguns sintomas característicos da depressão, porém não a definem com clareza.

As professoras percebem que a depressão infantil pode afetar a aprendizagem, a maioria delas explica que o aluno que se sente com a auto-estima baixa tem dificuldade de concentração e de memória e ainda perdem o interesse pela aula, deixando de aprender e, por conseqüência, prejudicando seu rendimento escolar.

Para as professoras, em relação à depressão infantil na escola, elas exercem a função de reconhecer os problemas emocionais que podem sugerir o quadro depressivo, comunicar aos responsáveis pelo aluno e a direção da escola para que esta criança seja encaminhada aos profissionais da saúde.

\section{- PSICÓlOGA JUDICIÁRIA}

A psicóloga judiciária comenta que a maioria das crianças que atende apresenta transtornos emocionais como ansiedade, conflitos, sentimento de rejeição, ambigüidade, depressão, insegurança, instabilidade entre outros, e geralmente vivenciam situações conflituosas ou traumáticas. Também destaca que a escola que não conta com uma equipe multidisciplinar deve encaminhar as crianças com indícios de depressão à profissionais qualificados. 


\section{- PSICÓlOGAS CLÍNICAS}

Duas psicólogas não responderam ao questionário, e a terceira psicóloga, que trabalha em consultório particular, apenas comentou que é incomum atender crianças com depressão infantil, e que por isso não conhece tanto sobre o assunto.

\section{- PSIQUIATRA}

O médico relata que são comuns os transtornos de humor na infância, com ansiedade de separação, TDAH e inclusive depressão infantil.

De acordo com sua experiência clínica, a maioria das crianças depressivas tem entre 04 e 08 anos de idade, sendo mais comum atender meninas com depressão. Ele já utilizou o CDI e destaca que é um bom instrumento diagnóstico, desde que esteja associado a uma avaliação clínica.

Para este médico psiquiatra, o professor tem o papel de reconhecer a depressão infantil em seus alunos e encaminhá-los para o tratamento, sendo importante manter-se informado sobre o assunto.

\section{CONSIDERAÇÕES FINAIS}

Ao comparar os estudos de Freud, Bowlby e Harlow a respeito dos transtornos emocionais na infância, é possível perceber que não é necessário que a estrutura da personalidade, como definiu Freud, esteja completamente desenvolvida para que uma criança vivencie a depressão nesta fase tão precoce da vida. Bowlby reconheceu sintomas depressivos em bebês quando privados do contato de suas mães e Harlow ainda comprovou através de experimentos com macacos com estrutura cerebral próxima a dos humanos, que situações estressoras podem causar crises depressivas. Atualmente sabe-se também que as situações estressoras e traumáticas podem desencadear depressão, inclusive na infância. 
As pesquisas sobre a depressão na infância são relativamente escassas apesar da crescente incidência desta doença nesta fase da vida. Não há nenhum tipo de material disponível nas bibliotecas da cidade, sendo necessário que as pesquisadoras adquirissem seus próprios livros.

A criança com quadro depressivo pode sofrer várias consequências como desinteresse, retardo psicomotor, dificuldade de concentração e raciocínio. A criança também pode deixar de participar significativamente das aulas e tem o rendimento escolar prejudicado. Com a mudança de comportamento, pensamento e sentimentos surgem outras consequências tais como: isolamento, anedonia, fobias, ansiedade e outros sintomas, maior retraimento social deixando de se relacionar com os colegas, com a professora e até com a família.

Mesmo sendo um problema psicológico, a depressão infantil também interfere no organismo da criança, provocando alterações do apetite e do sono e até dores somáticas. Desta forma, percebe-se que a depressão pode evoluir se não for diagnosticada e tratada precocemente, podendo acarretar agravamento do caso.

Tal situação é bastante preocupante já que, como vimos a depressão afeta a vida da criança em todos os seus âmbitos.

A aplicação do Inventário da Depressão Infantil possibilitou identificar um considerável número de crianças com sintomas sugestivos de depressão. A presença da depressão no contexto escolar mostra a necessidade de conhecimento sobre este quadro por parte do professor e o reconhecimento da gravidade do problema, pois uma criança com depressão pode ter a aprendizagem e o convívio social prejudicados.

Alguns profissionais defendem que a aplicação do CDI por professores seria um valioso instrumento para a realização de um pré-diagnóstico e encaminhamento da criança a profissionais especializados.

$\mathrm{Na}$ opinião das pesquisadoras, o CDI é um instrumento muito útil na identificação da depressão infantil, mas para obter o resultado esperado faz-se necessário que seu uso seja feito por profissionais treinados e qualificados. O uso do CDI por professores pode causar a estigmatização das crianças, pois o professor não possui preparo e nem o conhecimento necessário para aplicação de um teste psicológico, sendo então arriscada a sua aplicação, podendo contribuir para o progresso da depressão infantil.

De acordo com o especialista em depressão infantil, Dr. José Hércules Golfeto, psiquiatra e professor da USP, em entrevista cedida às pesquisadoras por correio 
eletrônico, evidenciou-se que há vários aspectos a se considerar, que podem interferir nos resultados do CDI, como a faixa etária das crianças, capacidade intelectual em compreender as questões, o meio em que vive e tamanho da amostra.

Portanto o CDI é capaz de identificar os sintomas que a criança apresenta, mas é indispensável à realização de entrevistas, observação e aplicação de outros tipos de testes psicológicos.

As professoras mostraram ter informações sobre depressão infantil, porém de maneira superficial e sem considerá-la como doença. Nota-se a preocupação das educadoras com seus alunos, bem como o interesse em compreender melhor a depressão infantil.

É importante afirmar que os professores não são responsáveis pelo diagnóstico da depressão infantil, visto que esta é uma tarefa que deve ser realizada por um profissional qualificado, mas cabe a estes professores encaminhar o aluno com sintomas depressivos para avaliação clínica.

Analisando a postura dos profissionais da área da saúde entrevistados, observase que o mais preparado para prestar atendimento à criança depressiva é o psiquiatra já que evidenciou conhecimentos fundamentados, seguindo os mesmos critérios da pesquisa bibliográfica apresentada na primeira seção.

Quanto às psicólogas observa-se posturas inseguras em relação ao assunto, apresentando dificuldade em fazer comentários a respeito da depressão infantil, ao ponto de não responderem ao questionário e afirmar a necessidade de pesquisa sobre o assunto. Esta situação causou impacto, já que são profissionais responsáveis pelo tratamento da depressão e encontram-se despreparadas ou então sabem muito pouco sobre a doença. Isto é preocupante, principalmente porque são psicólogas do departamento de saúde pública, ao qual as crianças têm mais acesso. Porém, verificamos que nossa pesquisa foi capaz de causar nestas psicólogas um desconforto em relação à falta de informações sobre a depressão infantil. Talvez este contato possa ter possibilitado a conscientização sobre a necessidade de um aprofundamento sobre o tema, já que elas afirmaram que necessitavam pesquisar mais sobre o assunto.

Muitas vezes a criança com depressão pode ficar sem apoio psicológico, por falta de acesso a profissionais capacitados e comprometidos com a questão da saúde emocional das crianças, principalmente na rede pública de saúde. Destaca-se a necessidade de existir na escola, psicólogos que possam se dedicar em acompanhar o 
tratamento dessas crianças, auxiliando o trabalho do professor e por conseqüência ajudando as famílias.

Reconhecer a existência de tal incidência de depressão infantil em nossas escolas leva a uma grande responsabilidade. Diante dos fatos, faz-se necessário a proposta de um projeto com objetivo de proporcionar assistência psicológica às crianças depressivas e às suas famílias, além de cursos de capacitação para os professores estarem mais preparados para identificar quadros que necessitem de encaminhamento para tornar eficaz a recuperação, desenvolvimento e reintegração ao convívio social.

\section{REFERÊNCIAS}

ANDRIOLA, W. B; CAVALCANTE, L. R. Avaliação da depressão infantil em alunos da pré-escola. Psicol. Reflex, Porto Alegre, v. 12, n. 2, 1999. Disponível em: $<\mathrm{http}: / / \mathrm{www}$.scielo.br/scielo.php?script=sci_arttext\&pid=S010279721999000200011\&lng=pt\&nrm=iso>. Acesso em: 29 Jul 2008. doi: 10.1590/S0102-79721999000200011

BAHLS, Saint-Clair. A depressão em crianças e o seu tratamento. São Paulo: Lemos Editorial, 2004.

BALLONE GJ, Alfred Adler. Sigmund Freud. PsiqWeb, 2005. Disponível em: http://virtualpsy.locaweb.com.br/index.php?sec=53\&art=159. Acesso em:19 Ago 2008.

BARRACHI, S. B. M. A escola normal de Ituverava: trajetórias e memórias. Ituverava. Ed. do Autor, 2006.

CARDOSO, S. H. As necessidades vitais dos bebês. Campinas, 2001. Disponível em: http://www.cerebromente.org.br/n13/experiment/affective/rhesus_p.html. Acesso: 16 Set 2008.

CRUVINEL, M; BORUCHOVITCH, E. Sintomas depressivos, estratégias de aprendizagem e rendimento escolar em alunos do ensino fundamental. Psicologia em estudo, Maringá, v. 9, n. 3, 2004. Disponível em: http://www.scielo.br/scielo.php?script=sci Arttex\&pid=S1413-73722994999399995\&Ing=PT\&nrm=iso. Acesso em: 22 Fev2008. doi: 10.1590/S1413-73722004000300005

FONSECA, M. H. G. et al. Sintomas depressivos em escolares.Pediatria (São Paulo) 2005; v.27, n.4, p.223-32. Disponível em: http://www.pediatriasaopaulo.usp.br/upload/pdf/1143.pdf. Acesso em: 23 ago. 2008.

GOLFETO, J.H.; VEIGA, M.H.; SOUZA, L.; BARBEIRA, C. Propriedades psicométricas do Inventário da Depressão Infantil (CDI) aplicado em uma amostra de escolares de Ribeirão Preto. Revista Psiquiatria Clínica. v.29, n.2, p.66-70, 2002.

Nucleus, v.6, n.2, out.2009 
Disponível em: http://www.hcnet.usp.br/ipq/revista/vol29/n2/pdf/66.pdf. Acesso em: 23 Ago 2008.

HEMERY, Jean-Jacques Roger. Depressão infantil. Revista do Professor - n. 80 http://www.projetospedagogicosdinamicos.com/artigo11.htm. Acesso em:14 ago. 2008.

LIMA, D. Depressão e doença bipolar na infância e adolescência. Jornal de Pediatria v. 80, n. 2 (Supl), p.11-20. ISSN 0021-7557, Porto Alegre, 2004. Disponível em: http://www.scielo.br/pdf/jped/v80n2s0/v80n2Sa03.pdf. Acesso em: 01 Jul 2008. doi: 10.1590/S0021-75572004000300003

MILLER, J. A. O livro de referência para a depressão infantil. São Paulo: M. Books do Brasil Editora Ltda., 2003.

SUKIENNIK, P. Bl; SEGAL, J.; SALLE, E. et al. Implicações da depressão e do risco de suicídio na escola durante a adolescência. Adolesc. Latinoam, vol.2, no.1, 2000. Disponível em: <http://ral-adolec.bvs.br/scielo.php?script=sci_arttext\&pid=S141471302000000200007\&lng=pt\&nrm=iso>. ISSN 1414-7130. Acesso: 14 Ago 2008. 